\title{
Exploring EFL Teachers' Perceptions of CLIL and Its Implementation in the Saudi EFL Context
}

\author{
Uzma Manzur Hashmi ${ }^{1}$ \\ ${ }^{1}$ Alfarabi Private College, Jeddah, Saudi Arabia \\ Correspondence: Uzma Manzur Hashmi, Alfarabi Private College, Jeddah, Saudi Arabia.
}

Received: June 6, 2019

Accepted: July 15, 2019 Online Published: September 29, 2019

doi:10.5539/ies.v12n10p114

URL: https://doi.org/10.5539/ies.v12n10p114

\begin{abstract}
This study aims to explore the perceptions of English as Foreign Language (EFL) teachers about the notion of Content and Language Integrated Learning (CLIL) in the Saudi EFL contexts. The veteran EFL teachers share their views regarding the application and implementation of CLIL approach. This study has looked into this issue from an interpretivist lens employing qualitative data collection technique, i. e. semi-structured interviews. The data were collected from 10 EFL teachers. The qualitative data were thematically analyzed that led to four major themes. The key findings reveal that CLIL is not a frequently used concept in this part of the world; however, its usefulness and effectiveness are recognized by the participants who also express their views about the pros and cons and other practical constraints that might affect the implementation of CLIL programs in the Saudi EFL context. One of the major issues that teachers have highlighted is the training programs that should encompass the idea of CLIL and train EFL teachers on the latest teaching skills to upgrade their pedagogical repertoire. Based on the findings, the study has suggested directions for the future researchers to fill the gap in the existing literature and investigate the phenomenon of CLIL in more depth in order to acknowledge its significance in the light of the Vision 2030
\end{abstract}

Keywords: CLIL, exploratory study, Saudi EFL context, teachers' perceptions

\section{Introduction}

The emergence of English as a global lingua franca has incurred changes in many educational programs around the world in order to meet the requirements of the job market and enhance social integration of the language users. Since foreign languages have become crucial to various educational systems (Nunan, 2003), CLIL programs have become popular to improve learners' foreign language skills. The aims of such programs are not only to develop learners' linguistic competence, but to focus on "content subject competence, intercultural competence, content subject methodologies and evaluation" (Coyle, 2007, p. 557). The term CLIL was coined by the researchers, practitioners and administrators working under the European Commission. According to them, Content and Language Integrated Learning was defined as: "a dual-focused educational approach in which an additional language is used for the learning and teaching of both content and language" (Coyle, Hood, \& Marsh, 2010, p. 1). The approach received great response from teachers in different western contexts mainly due to the reason that: "it placed both language and non-language content in a form of continuum, without implying preference for one or the other" (Marsh, 2002, p. 58). According to Marsh (2000), CLIL program is a great way to nurture 'a feel good' attitude among foreign language learners which leads to their higher level of proficiency and language competence. Marsh (2000) further elaborates:

A major outcome of CLIL is to establish not only competence in two languages, but also nurture a 'can do' attitude towards language learning in general. So very often the CLIL language will itself only be a platform by which the youngster may ultimately take an interest in other languages and cultures as well. If the child has a language which is not the language of the wider environment, then CLIL can lead to an even greater appreciation of that home language. (Marsh, 2000, p. 10)

In a foreign language teaching and learning context, learners often need exposure to the target culture through teaching materials in a bid to develop their linguistic and cultural competence of the target language. Since, EFL students often lack access to the authentic culture, their only available source remains the classroom teacher, textbooks and online material that help them learn the target language in a natural language learning context. As research findings indicate that exposure to the target culture significantly enhances learners' linguistic competence 
(e.g. Serrano, 2007, 2011; Serrano \& Muñoz, 2007), EFL learners should be offered opportunities to take part in a wide-range of $\mathrm{L} 2$ social contexts.

It is believed that CLIL as a teaching approach can equip EFL teachers to create a learning milieu that enables language learners to interact with social contexts, cultural intricacies and linguistic complexities in a classroom setting. Studies conducted on the topic of SLA (Second Language Acquisition) offer a great insight into effectiveness of CLIL programs as they trigger conditions that support naturalistic language teaching and learning and gives more time and exposure to learners with an objective for language use in classroom environment (Dalton-Puffer \& Smit, 2007).

Although CLIL has been developing in many western countries, in the GCC region in general and in the Saudi EFL context in particular, there is a serious dearth of empirical studies to unearth the usefulness, effectiveness and implementation of this language teaching approach. The key objectives of this small-scale qualitative study are to explore and understand the views of English as Foreign Language (EFL) teachers regarding the applicability of CLIL in the Saudi EFL context. Their perceptions will help us identify the challenges and possibilities linked to the application and implementation of CLIL in the Saudi Arabian EFL context.

This small-scale qualitative study aims to answer the following two overarching research questions.

1) What are the EFL teachers' perceptions of CLIL program in the Saudi EFL context?

2) How does CLIL program facilitate or hinder the EFL teachers' ability to teach Saudi EFL learners?

\subsection{Context of the Study}

This small-scale qualitative study is conducted in a Saudi Arabia university that runs a foundation year program to cater to the learning needs of more than 8000 EFL learners each year. The faculty is comprised of more than 200 EFL teachers from various countries around the world who have diverse educational, cultural and linguistic backgrounds. These teachers are qualified language teachers with qualifications, such as CELTA, DELTA, PgDip in TESOL, MA TESOL etc. from renowned institutions. The foundation year program has four modules per year and each module has 7 weeks teaching and assessment. The program follows the Common European Framework (CEF) that helps students know their level of proficiency at the beginning and at the end of the program.

\section{Literature Review}

\subsection{The 4 Importance Cs of CLIL Approach}

CLIL is an integrated approach that equips language teachers with tools and strategies to create an interactive and conducive learning environment that contributes to the learners' linguistic and cultural competence. Coyle (1999) has suggested a framework that is consisted of 4Cs which are mainly used for planning lessons: 1) Content; 2) Communication; 3) Cognition; 4) Culture. Content explains and highlights the topic. Communication focuses on the mode and means of communication and explains the language that learners need to use for undertaking different language tasks in classrooms. Cognition underscores the importance of those skills which students need to learn and polish for completing a task. Culture is often displayed in language lessons and learners need to develop their ability to decode cultural references stated in the topic/lesson.

These 4Cs can be deemed as main principles or a conceptual framework that offers teachers a foundation to develop pedagogies and pay attention to the link between content, communication, cognition and culture while planning lessons. It would be interesting to see how these 4Cs or this conceptual framework works with EFL teachers in the Saudi EFL context as no prior research has considered this aspect of language teaching and learning before.

\subsection{CLIL as an Interactive Tool in EFL Classrooms}

Interaction is one of the key goals of CLIL as it can be seen in the 4Cs that communication holds an important place in the framework. In a classroom setting, it refers to teacher-learners communication as well as learners' exposure to new language items and how they learn them. The CLIL approach establishes the fact that learning is not merely an internal and cognitive process, rather, it is interaction and communication that leads to acquiring knowledge and developing understanding of a language item. Furthermore, this approach helps learners enhance their existing knowledge through sharing and discussing ideas. This leads to the learners' autonomy and independence in classroom.

Foreign language teaching and learning has embraced the notion of CLIL in various contexts that often concentrates on its pedagogical design as a teaching approach. A plethora of studies show the interactional aspect of CLIL that generates a constructive and meaningful communication between the learners and ensures negotiation of meanings through mutual understanding. In oral activities, speakers tend to apply various strategies that help 
learners overcome communicative hindrances (Mariotti, 2006, 2007; Foster \& Ohta, 2005). These strategies are often based on negotiation of a meaning in L2 classroom environment (Foster \& Ohta, 2005; Musumeci, 1996). Studies on the negotiation of meaning and interactive aspect of CLIL illustrate that CLIL as an approach creates more opportunities for learners to deliberate on the content and language simultaneously and offers a rich and conducive learning environment to L2 learners which they may not experience in a traditional EFL classroom (Badertscher \& Bieri, 2009; Lochtman, 2007). As the literature has highlighted the role and significance of CLIL as an interactive tool, there is lack of empirical evidence in the context of Saudi Arabia to determine whether CLIL can be an effective tool for EFL teachers with regards to their effort towards providing interactive opportunities for EFL learners. Nevertheless, this study intends to fill that gap.

\subsection{Learners 'Sociocultural Status and Its Impact on CLIL}

As the concept of CLIL has been derived from western ESL contexts, it might encounter challenges and obstacles in various EFL contexts. Studies show that the sociocultural status of learners has a very strong impact on the L2 learners' ability to understand and apply CLIL strategies in classroom (Laurén, 1994; Lasagabaster, 1998). It is observed that EFL learners with an elite sociocultural status perform better than those who have a lower sociocultural status. Similarly, Furnham and Heaven (1998) found out that sociocultural status can strongly influence learners' attitude towards classroom teaching and learning which consequently impacts on their overall academic performances. From the above studies, it can be inferred that learners' low or high social class/status can influence their performance and as a result it can affect the teaching practices. Therefore, CLIL as a western concept might not be applicable in a context where social and cultural equality does not exist. Classrooms can have students from different and varied social class and their difference in attitude can challenge the teachers' approach to vary, supplement, customize and differentiate teaching materials to meet the learners' learning needs. However, in the Saudi EFL context there is no reference available that could denote the significance of sociocultural status on the EFL learners' attitude and teachers' pedagogical practices. More research in this regard will yield interesting results.

Literature also suggests that CLIL can be a useful tool if students receive support from the parents outside their classrooms. Parental support can play a vital role and teachers' efforts to motivate EFL learners should not suffice (Donitsa-Schmidt et al., 2004). Lack of support from parents can increase the teachers' responsibility to monitor and record the progress of the learners, particularly, in large and mixed-ability classrooms.

\subsection{Issues and Challenges in Implementation of CLIL}

The implementation of CLIL is considered a difficult task due to the lack of qualified language teachers, sufficient budges and other logistic resources. Though it varies from context to context, the main challenges remain the same in different educational contexts around the world. For example, most of the language schools do not offer sufficient professional learning and development support to EFL teachers in their workplaces. As a result, they could not implement the CLIL program in their classrooms. Since most of the teacher training certificates do not pay attention to the CLIL element, therefore, teachers need to develop their existing knowledge of the approach in order to integrate and apply its various features in their day-to-day classes.

Large classrooms with mixed-ability students are a common phenomenon in most EFL contexts which teachers find it as a challenge. Teachers often fail to reach every individual student in such classrooms and students often feel ignored. With CLIL approach, every student needs to receive attention from teacher and get exposure to the target language which will enable them to interact with peers. Since it's a daunting task to deal with such situations, teacher training programs need to encompass these issues and address them effectively. According to Coonan (2011), "a large-scale teacher population without the language qualifications required for quality CLIL teaching" (p. 4). In such a situation, teachers need a CLIL-based training as well as professional collaboration at the workplace to tackle any obstacles that might hinder their teaching practices (Conn, 2010; Leavitt, 2006).

Research shows that the existing teacher development programs that aim to cater to the professional learning needs of the EFL teacher are not adequate mainly owing to the numbers and complexity of variables that influence CLIL programs (e.g. Hillyard, 2011; Lasagabaster \& Ruiz de Zarobe, 2010; Pistorio, 2009). For instance, trainers require to do need analysis of teaching practices, evaluate the context and programs in a specific educational context, teachers' prior experiences and educational background, learners' culture and their learning needs (Banegas, 2012; Dalton-Puffer, 2011; Hillyard, 2011; McDougald, 2009). This could also be achieved through strong collaboration and teamwork between EFL teachers and subject teachers in a given context (Biçaku, 2011). Collaborative practices and formal professional training can help both content and language teachers to devise plans and implement the most appropriate language tasks in classrooms that would yield positive results for teachers and learners. 
Another major issue could be the lack of time, as in CLIL approach, the integration of 4Cs requires a lot of time and effort to plan lessons, devise strategies and think about anticipated problems. If teachers lack training and skills to consider various aspects of CLIL and integrate 4Cs into their lesson plans, their lessons will not produce the required or desired results.

\section{Study Design}

\subsection{Interpretive Paradigm}

The present study has adopted a naturalistic and exploratory approach to consider the experiences, perceptions and multiple realities to understand the phenomenon of CLIL approach and its applicability in the Saudi context. For this purpose, the interpretive paradigm underpins the philosophical foundations of this inquiry as interpretive research reflects constructivist, naturalistic and qualitative features (Robson, 2002). Smith (1987) believes that "for interpretive approaches, the object field to be studied is the acts and meanings ascribed to events by actors in a particular social context" (p. 140). Similarly, Marshall and Rossmans (1999) state that "for a study focusing on individual lived experience, the researcher could argue that one cannot understand human actions without understanding the meaning that participants attribute to these actions, their thoughts, feelings, beliefs, values, and assumptive worlds" (p. 57). One of the main advantages of this interpretive approach was that as a researcher I found myself immersed in the study as it allowed me to interact with teachers and ask them questions which often triggered my mind. Borg and Gall (1983) has stated this point that "by being actively involved in the situation that the researcher is observing, the researcher often gains insights and develops interpersonal relationships that are virtually impossible to achieve through any other method" (p. 26).

\subsection{Method of Data Collection}

The main objective of this small-scale qualitative study was to achieve a deeper understanding of the CLIL approach in the Saudi EFL context which motivated me to utilize qualitative techniques for data collection purposes (Jupp, 2006). For this purpose, 10 semi-structured interviews were conducted with 10 EFL teachers at their convenience. Semi-structured interview was a great choice as it is "a uniquely sensitive and powerful method for capturing the lived experiences and lived meanings of the subjects' everyday world" (Kvale, 2007, p. 11). Moreover, this method for data collection helps "to seek in-depth understanding about the experiences of individuals and groups, commonly drawing from a small sample of people, selected purposively. Such types of interviews are called semi-structured" (Scott \& Usher, 2006, p. 147).

Ten EFL instructors were interviewed using the English language. Each interview lasted for approximately 40 to 50 minutes. All the interviews were audio recorded on a Sony digital recorder and the files were transferred to a password protected laptop. Having transcribed all the interviews, MS-Word files were created with the participants' pseudonyms to ensure their anonymity.

\subsection{Participants}

Ten EFL teachers from various countries and backgrounds took part in this study. I used a purposive sampling strategy (Patton, 2002) in a bid to access the participants who were in the best position to share their views and experiences (Cohen et al., 2011). Before the start of the study, I sought their informed consent to participate in this study and explained the aims and the expected outcomes of the study. Moreover, I assured them of their anonymity and confidentiality of their views as they chose pseudonyms for themselves (Neuman, 2006).

\subsection{Data Analysis}

The qualitative data generated from 10 interviews were imported to NVivo11 software in order to organize and examine the participants' responses in an efficient manner. I used open coding (Miles \& Huberman, 1994; Creswell, 2012) for data analysis. The first round of reading of the data resulted into 110 open codes. In the second stage, I merged the identical codes and reduced them to 40 . The examination of the codes was a reiterative process that involved reading the codes and participants' responses serval times in order to ensure that the assigned codes match the content. Moreover, I also concentrated on emerging new codes and the research questions (Miles \& Huberman, 1994; Newby, 2010). In the final stage of the data analysis, the codes were collapsed into 10 different categories and sub-categories which generated four overarching themes. The emerging themes were examined in the light of the research questions to see if they answer the research questions and achieve the set goals of the study.

\section{Findings and Discussion}

The aim of the study was to understand the nature of CLIL approach and see how EFL teachers perceive its applicability in the Saudi EFL context. As the semi-structured interviews generated qualitative data which were thematically analyzed, this section presents the findings in the form of the participants' views (direct quotes) and 
discuss them in the light of the existing literature.

\subsection{EFL Learners' Attitude to CLIL}

The findings suggest that EFL learners often have a poor attitude towards English language, particularly, lower level learners who lack motivation and purpose to learn English. This creates a major issue for the teachers to bring variety in their lesson and introduce innovative activities. The following quotes are representative of what the participants said about the learners' attitude and its impact on their teaching strategies, such as CLIL.

When students have repeated the semester a couple of times, used the same book a few times and have no obvious purpose for learning English, it makes the teacher's job more difficult. I often come across students in lower level classes, who hardly understand the instruction in English. In such a scenario, I do not think that CLIL as an approach can be adopted in an effective way. (Hina)

CLIL is a good way of teaching higher level students who can undertake complex task and activities. The variety of techniques and tools used by teachers with high proficiency students always produce good results. I have seen that low proficiency students like to complete basic tasks and activities which do not challenge their linguistic and cognitive skills. (Pinkie)

In my opinion, attitude is more important than aptitude. Learners may not have the required skills to complete a task, but if they are motivated, they will certainly do well. For CLIL, I strongly believe that you need to have stronger and highly motivated students who could benefit from exposure to advance linguistic and cultural complexities of the target language. (Alaa)

Similar to what (Badertscher \& Bieri, 2009; Lochtman, 2007) established in their studies, we can conclude that a positive learner's attitude and motivation of EFL learners are equally important factors that can facilitate the implementation of CLIL approach. If learners have an urge for learning, they will perform better and achieve their academic goals.

\subsection{EFL Teachers' (Lack of) Familiarity with CLIL}

It is interesting to note that CLIL as a teaching approach seems to be a novel concept in this part of the world. Since most of the teachers have teaching qualifications, such as CELTA and DELTA, they are more familiar with Communicative Language Teaching (CLT) which is a predominantly known and used concept. The findings of this study are very much in line with the literature (e.g. Coonan, 2011; Conn, 2010; Leavitt, 2006; Hillyard, 2011; Lasagabaster \& Ruiz de Zarobe, 2010; Pistorio, 2009; Dario Luis Banegas, 2012; Dalton-Puffer, 2011; Hillyard, 2011; McDougald, 2009). The participants have expressed their concerns regarding the insufficient professional development support being offered to them at the workplace. Moreover, lack of time, resources and proper training would lead to their inability to implement the proposed framework of CLIL in the Saudi EFL context. The stringent pacing guide and a prescribed syllabus are the two major constraints that EFL teachers often talk about in this context. The following excerpts from the participants illustrate their views about CLIL approach.

It's not a very commonly used concept in our institution. We often discuss CLT, but rarely mention CLIL. Probably, our focus is mainly on language and not the content. (Sana'a)

Even if I know about CLIL and its various advantages, I won't be able to implement it in my classrooms because I don't have time for experimentation. The pacing guide needs to be followed and that is mandatory for us to finish the syllabus in 6 weeks. (Pinkie)

If it comes from the top management, I will definitely learn more about it and try to make it a part of my daily lesson plans. However, I don't think it has been advised by the trainers in this context as most of the workshops are more focused on the communicative part of the language learning and teaching whereas content and culture are not given importance. (Sono)

The above extracts also indicate the fact that teacher development programs do not consider CLIL as an important aspect of EFL teaching in the Saudi context. If the purpose of language teaching is to develop students linguistic, communicative and cultural competence, trainers and mentors should take CLIL into consideration to serve the interests of EFL learners and make them competent and proficient speakers for the job market.

\subsection{CLIL as a Communicative Tool in EFL Classrooms}

There is a common consensus among the EFL teachers in this study that the applications of CLIL in EFL classroom can lead to positive outcomes due to the $4 \mathrm{Cs}$ framework which helps learners become proficient in the target language. Beena shared her views about the advantages of CLIL:

CLIL has a number of positive aspects that can create an encouraging learning milieu for EFL learners. If 
the 4Cs framework is applied properly, learners can benefit a great deal from it and teachers can have a sense of fulfillment. CLIL has a strong focus on communication and interaction which can lead to strong peer relationship as well as develop good rapport with students and teachers.

As the literature supports the view that CLIL has the potential to generate interaction between the students and create a collaborative learning environment, this study also proves the point that interaction is a significant quality of CLIL which will certainly improve the English proficiency of EFL learners (Mariotti, 2006, 2007; Foster \& Ohta, 2005; Foster \& Ohta, 2005; Musumeci, 1996). The meaningful interaction helps the learners to negotiate meaning and purpose of the teaching tasks. Since EFL contexts often fail to provide opportunities outside classrooms where students can interact with others while using English language, CLIL becomes a pivotal tool in this regard. The following excerpts are evident examples of what the participants of this study shared.

Whatever method is preferred by the teachers, one thing is for sure that interaction must take place. When students are engaged in meaningful tasks, the classroom will become a natural place for learning. I believe, CLIL has the potential to provide learners with activities that can lead to interaction and communication. Moreover, the interaction will mainly be about the content of the lesson which will also focus on the language use, therefore, the language, vocabulary and other expressions related to the topic will become part of the learners 'permanent memory. (Beena)

In our context, classroom is the only place that can offer students a chance to practice English language. Hence, teachers need to devise strategies that could lead to more interaction and communication in the classroom. I think, CLIL can do that for teachers and students. (Sana'a)

In the wake of globalization, EFL teachers need to assess and meet the linguistic needs of their learners. It is an extremely challenging task for teachers as the management has different expectations whereas learners expect us to teach or give them input that meets their learning needs. In such a situation, CLIL approach can achieve objectives set by the leadership as well as the students because the end goal is always to develop communicative, linguistic and cultural competence of the students. (Sono)

\subsection{Challenges Associated to CLIL in EFL Context}

As the reviewed literature has highlighted various issues related to the implementation of CLIL, such as time constraints, teachers' lack of preparedness and students' negative attitude (discussed in section 4.2), this study goes beyond these obstacles. The participants believe that CLIL can be a disaster just like CLT or any other western-borrowed concept. The key reason that has been pointed out by the participants is the cultural differences. In Saudi Arabia, monolingual and mono-cultural students may not be as extrovert as western students in the ESL context. Their reserved nature may hinder the implementation of CLIL. Secondly, students often need to use the language for their specific purposes in the Saudi context; therefore, they may not require learning about the target culture in depth.

I consider CLIL an effective approach to teaching a foreign language, however, it's not necessary that every western concept works in our setting. See CLT. Can it work with zero level, repeater students who have zero motivation and interest? No methodology works in such circumstances. (Alaa)

CLIL exposes EFL learners to the English culture, but do our students really need to know that? I don't think so. Our students need to develop practical and technical skills to develop their speaking and writing abilities, so they can work in their own country, Saudi Arabia. They don't go abroad for jobs, thus, there is no need to explore other cultures. I believe, we can still teach them the English language without being exposed extensively to its culture. (Sarah)

Another major concern that has surfaced in this study is the lack of awareness of the policy makers, course designers and syllabus creators in this context. The participants believe that the top management needs to understand and recognize the significance of CLIL and integrate it in the curriculum. This will have a trickle-down effect on the teachers who will have to incorporate CLIL components in their lesson plans.

Anything that is introduced and made mandatory by the dean and vice deans will become part of the day-to-day practice. The question is whether they have knowledge about CLIL and its significance? (Pinkie)

If we consider CLIL a success story in other parts of the world, I think it should be introduced in this part of the world as well. Importantly, the current curriculum and syllabi do not have a strong focus on CLIL; however, if teachers push for it, there is every chance that it will be initiated soon. Let's hope, the top bosses realize and give it a try. (Sono) 
The above excerpts are instances of the teachers' awareness and understanding of this new concept. Their call for the introduction of CLIL has significance as they know that the application of its all or some features will nevertheless add to the learning and development of the Saudi EFL learners. Moreover, it will provide teachers a chance to learn and improve their teaching repertoire.

\section{Future Research Directions}

The notion of CLIL appears to be a novel concept; however, it has been understood and received well by the EFL teachers in Saudi Arabia. Since, more knowledge of the CLIL approach and programs is required, future research should investigate the issue from various aspects to determine the professional learning needs of the EFL teachers to effectively integrate its elements in their lesson plans.

Apparently, CLIL has not been incorporated in language curriculums. In order to achieve the Saudi Vision of 2030, it is important to consider CLIL as a launching pad for EFL learners to compete in international market and increase their job securing opportunities. Future research may explore this facet of CLIL approach in different universities to raise awareness and achieve good results for students.

Research on the implementation of CLIL can adopt qualitative and quantitative methods to achieve fuller and wider understanding of the phenomenon. It is important to conduct longitudinal studies on the issue and see how CLIL approach can benefit the learners in the Saudi EFL context.

\section{Conclusion}

This small-scale qualitative study has adopted an interpretive approach to explore the EFL teachers' perceptions of the CLIL approach in the Saudi EFL context. The participants expressed their views about the pros and cons and practical constraints that might affect the application and implementation of CLIL programs in the Saudi EFL context. The most important findings of the study suggest that CLIL might be a very popular and effective teaching approach in western contexts, however, its applicability and suitability might not produce good results in the Saudi context due to cultural, linguistic and motivational differences of the Saudi EFL students. Nevertheless, the participants are of the view that learners with a positive attitude and higher level of English proficiency might encourage the teachers to incorporate CLIL elements in their lesson plans. The findings have also suggested practical constraints, such as lack of time and resources, support from the top management and proper and more rigorous professional development training in their working context. Although the EFL teachers consider CLIL an effective tool in creating and developing a learning environment that can facilitate learners' communicative and linguistic competence; however, the teachers on this study were not fully aware of all the different aspects, features and characteristics of CLIL. In this case, the EFL teachers demanded for more context-specific training that will equip them with top-notch pedagogical tools in the most demanding context of Saudi EFL teaching and learning. The future directions stated in this study have highlighted a gap in the existing literature and the scope of the topic that can be investigated in more depth to help teachers, course designers and policy makers understand the notion of CLIL and its significance in the light of the Vision 2030.

\section{References}

Banegas, D. L. (2012). CLIL teacher development: Challenges and experiences. Latin American Journal of Content and Language Integrated Learning, 5(1), 46-56. https://doi.org/10.5294/laclil.2012.5.1.4

Biçaku, R. C. (2011). CLIL and teacher training. Paper presented at the Procedia-Social and Behavioral Sciences.

Borg, S. (2006). Teacher cognition and language education: Research and practice. London, UK: Continuum.

Cohen, L., Manion, L., \& Morrison, K. (2011). Research methods in education. NY, USA: Routledge.

Conn, C. E. (2010). Learning the Hard Way (But Still Learning!): Using Team Teaching as a Vehicle for Pedagogical Change. Business Communication Quarterly, 73, 87-91. https://doi.org/10.1177/1080569909358098

Coonan, C. M. (2011). CLIL in (Language) Teacher Training. Studi Di Glottodidattica, 2(1), 114.

Coyle, D (1999). Theory and planning for effective classrooms: supporting students in content and language integrated learning contexts. In J, Masih (Ed.), Learning through a Foreign Language. London: CILT.

Coyle, D. (2007). Content and language integrated learning: Towards a connected research agenda for CLIL pedagogies. The International Journal of Bilingual Education and Bilingualism, 10, 543-562. https://doi.org/10.2167/beb459.0

Coyle, D., Hood, P., \& Marsh, D. (2010). CLIL: Content and language integrated learning. Cambridge, UK: 
Cambridge University Press.

Creswell, J. W. (2012). Qualitative inquiry and research design: Choosing among five approaches. London, UK: Sage.

Dalton-Puffer, C. (2011). Content-and-language integrated learning: From practice to principles? Annual Review of Applied Linguistics, 31, 182-204. https://doi.org/10.1017/S0267190511000092

Dalton-Puffer, C., \& Smit, U. (Eds.) (2007). Empirical perspectives on CLIL classroom discourse. Frankfurt, Vienna: Peter Lang. https://doi.org/10.3726/978-3-653-01829-5

Donitsa-Schmidt, S., Inbar, O., \& Shohamy, E. (2004). The effects of teaching spoken Arabic on students' attitudes and motivation in Israel. The Modern Language Journal, 88, 217-228. https://doi.org/10.1111/j.0026-7902.2004.00226.x

Foster, P., \& Ohta, A. (2005). Negotiation of meaning and peer assistance in second language classrooms. Applied Linguistics, 26, 402-430. https://doi.org/10.1093/applin/ami014

Furnham, A., \& Heaven, H. S. (2011). First steps in CLIL: Training the teachers. Latin American Journal of Content and Language Integrated Learning, 4(2), 1-12. https://doi.org/10.5294/lacli1.2011.4.2.1

Jupp, V. (2006). The Sage Dictionary of Social Research Methods. SAGE Publication Ltd. London. https://doi.org/10.4135/9780857020116

Kvale, S. (2007). Doing Interviews. London: Sage. https://doi.org/10.4135/9781849208963

Lasagabaster, D. (1998) Learning English as an L3. ITL Review of Applied Linguistics, 121(1), 51-84. https://doi.org/10.1075/itl.121-122.05las

Lasagabaster, D., \& Ruiz de Zarobe, Y. (Eds.) (2010). CLIL in Spain: Implementation, results and teacher training. Newcastle upon Tyne, UK: Cambridge Scholars Publishing.

Laurén, U. (1994). The written production of bilingual and monolingual students. Performance and creativity, Vaasa, Finland, Universitas Wasaensis.

Leavitt, M. (2006). Team-teaching: The benefits and challenges. Speaking of Teaching, 16(1), 14.

Mariotti, C. (2006). Negotiated interactions and repair patterns in CLIL settings. In C. Dalton-Puffer, \& T. Nikula (Eds.), Vienna English Working Papers (Views) (Special Issue: Current Research on CLIL), 15(3), $33-41$.

Mariotti, C. (2007). Interaction Strategies in English-Medium Instruction. Milan: Franco Angeli.

Marsh, D. (2000). An introduction to CLIL for parents and young people. In D. Marsh, \& G. Lange (Eds.), Using languages to learn and learning to use languages. Jyväskylä, Finland: University of Jyväskylä.

Marsh, D. (2002). CLIL/EMILE-The European dimension: Actions, trends and foresight potential. Jyväskylä, Finland: UniCOM, Continuing Education Centre, University of Jyväskylä. Retrieved from http://ec.europa.eu/education/languages/pdf/doc491_en.pdf

Marshall, C., \& Rossman, G. B. (2010). Designing qualitative research. London, UK: Sage.

Miles, M. B., \& Huberman, A. M. (1994). Qualitative data analysis: An expanded source book. CA, USA: Sage.

Musumeci, D. (1996). Teacher-learner negotiation in content-based instruction: Communication at cross-purposes? Applied Linguistics, 17, 286-325. https://doi.org/10.1093/applin/17.3.286

Neuman, W, L. (2006). Social research methods: Qualitative and quantitative approaches. US: Pearson Education: Inc.

Newby, P. (2010). Research methods for education. Harlow, UK: Pearson Education Ltd.

Nunan, D. (2003). The impact of English as a global language on educational policies and practices in the Asia-Pacific region. TESOL Quarterly, 37, 589-613. https://doi.org/10.2307/3588214

Patton, M. Q. (2002). Qualitative interviewing. Qualitative research and evaluation methods, 3, 344-347.

Pistorio, M. I. (2009). Teacher training and competences for effective CLIL teaching in Argentina. Latin American Journal of Content and Language Integrated Learning, 2(2), 37-43. https://doi.org/10.5294/laclil.2009.2.2.14

Robson, C. (2002). Real world research: A resource for social scientists and practitioner researchers (Vol. 2). Oxford, UK: Blackwell Publishers. 
Scott, D., \& Usher, R. (2011). Researching education: data, methods and theory in educational enquiry. London, UK: Continuum International Publishing Group.

Serrano, R. (2011). The time factor in EFL classroom practice. Language Learning, 61, 117-143. https://doi.org/10.1111/j.1467-9922.2010.00591.x

Serrano, R., \& Muñoz, C. (2007). Same hours, different time distribution: Any difference in EFL? System, 35, 305-321. https://doi.org/10.1016/j.system.2007.02.001

Smith, M. L. (1987). Publishing qualitative research. American Educational Research Journal, 4(2), 173-183. https://doi.org/10.3102/00028312024002173

\section{Copyrights}

Copyright for this article is retained by the author(s), with first publication rights granted to the journal.

This is an open-access article distributed under the terms and conditions of the Creative Commons Attribution license (http://creativecommons.org/licenses/by/4.0/). 